\title{
Wear and Corrosion Resistance of Plasma Electrolytic Oxidation Coatings on 6061 Al Alloy in Electrolytes with Aluminate and Phosphate
}

\author{
Zhenjun Peng ${ }^{1,2}$, Hui Xu ${ }^{1, *}$, Siqin Liu ${ }^{2}$, Yuming $\mathrm{Qi}^{2}$ and Jun Liang ${ }^{2, *} \mathbb{D}$ \\ 1 College of Petrochemical Engineering, Lanzhou University of Technology, Lanzhou 730050, China; \\ zhenjunpeng2010@licp.cas.cn \\ 2 State Key Laboratory of Solid Lubrication, Lanzhou Institute of Chemical Physics, Chinese Academy of \\ Sciences, Lanzhou 730000, China; liusiqin18@mails.ucas.edu.cn (S.L.); qym87@sina.com (Y.Q.) \\ * Correspondence: xuhui@lut.cn (H.X.); jliang@licp.cas.cn (J.L.); \\ Tel.: +86-931-496-8244 (H.X.); +86-931-496-8381 (J.L.)
}

Citation: Peng, Z.; Xu, H.; Liu, S.; Qi, Y.; Liang, J. Wear and Corrosion Resistance of Plasma Electrolytic Oxidation Coatings on $6061 \mathrm{Al}$ Alloy in Electrolytes with Aluminate and Phosphate. Materials 2021, 14, 4037. https://doi.org/10.3390/ma14144037

Academic Editor: Tomasz

Trzepiecinski

Received: 25 June 2021

Accepted: 16 July 2021

Published: 19 July 2021

Publisher's Note: MDPI stays neutral with regard to jurisdictional claims in published maps and institutional affiliations.

Copyright: () 2021 by the authors. Licensee MDPI, Basel, Switzerland. This article is an open access article distributed under the terms and conditions of the Creative Commons Attribution (CC BY) license (https:// creativecommons.org/licenses/by/ $4.0 /)$.

\begin{abstract}
Phosphate and aluminate electrolytes were used to prepare plasma electrolytic oxidation (PEO) coatings on 6061 aluminum alloy. The surface and cross-section microstructure, element distribution, and phase composition of the PEO coatings were characterized by SEM, EDS, XPS, and XRD. The friction and wear properties were evaluated by pin-on-disk sliding tests under dry conditions. The corrosion resistance of PEO coatings was investigated by electrochemical corrosion and salt spray tests in acidic environments. It was found that the PEO coatings prepared from both phosphate and aluminate electrolytes were mainly composed of $\alpha-\mathrm{Al}_{2} \mathrm{O}_{3}$ and $\gamma-\mathrm{Al}_{2} \mathrm{O}_{3}$. The results demonstrate that a bi-layer coating is formed in the phosphate electrolyte, and a single-layered dense alumina coating with a hardness of $1300 \mathrm{HV}$ is realizable in the aluminate electrolyte. The aluminate PEO coating had a lower wear rate than the phosphate PEO coating. However, the phosphate PEO coating showed a better corrosion resistance in acidic environment, which is mainly attributed to the presence of an amorphous $\mathrm{P}$ element at the substrate/coating interface.
\end{abstract}

Keywords: aluminum alloy; plasma electrolytic oxidation; phosphate; aluminate; wear; corrosion

\section{Introduction}

The awareness of sustainable development and environmental stability has been deeply rooted in various fields in recent decades. Accordingly, the target of reducing the consumption of natural resources and decreasing pollution has been established. As a consequence, aluminum ( $\mathrm{Al}$ ) alloys have gained more and more attentions due to its characteristic of light weight. They are considered as desirable materials to replace the traditional ferrous materials to some extent. In terms of the properties, $\mathrm{Al}$ alloys are characterized by high specific strength and low specific weight compared with conventional ferrous material, wide adaptability of heat treatment, and superior processability for casting, forging, welding, and machining [1-3]. Up to now, they have been widely employed as structural components in the fields of spacecraft, aircraft, automotive, and $3 \mathrm{C}$ products [4-6]. However, $\mathrm{Al}$ and its alloys are susceptible to be corroded both in the acidic and the alkaline environments, which is also a fatal shortcoming for its natural oxide film. Moreover, the poor wear resistance limits their large-scale applications $[7,8]$.

For enhancing the combination properties of $\mathrm{Al}$ alloys, a large number of surface treatments have been developed, such as anodizing [9], thermal oxidation [10], vapor deposition [11], and plasma electrolysis [12]. Among these surface treatments, plasma electrolytic oxidation (PEO) is considered as an effective process to fabricate ceramic oxide coatings on $\mathrm{Al}$ alloys. The PEO coatings have superior mechanical properties and chemical stability that can protect the $\mathrm{Al}$ alloy substrate from corrosion and wear failures [13,14]. 
It is known to all that PEO is a multifactorial process. The electrolyte component plays a critical role, affecting the surface composition, morphology, structure, and properties of PEO coatings. Generally, the PEO electrolytes are alkaline silicate [15], phosphate [16], and aluminate solutions [17], according to their main components.

Many works reported that the PEO coatings prepared from silicate electrolyte were composed of silica, alumina, and mullite [18-22]. In contrast, the PEO coatings prepared from phosphate and aluminate were mainly composed of alumina compounds [23-26], although a trace of phosphorus was usually detected in the PEO coatings prepared in phosphate-based electrolyte. Additionally, the alumina also endowed the relevant PEO coatings with a better anti-corrosion and anti-wear performance. However, few works have been made on a comparison between the alumina-dominant coatings fabricated in the phosphate-based and the aluminate-based electrolytes. In this work, the effects of electrolytic components on the features of the PEO coatings were researched, and the tribological properties and acidic corrosion resistance was measured.

\section{Experimental Details}

\subsection{PEO Process}

Rectangular samples of $6061 \mathrm{Al}$ alloy (weight fraction: $0.88 \% \mathrm{Mg}, 0.37 \% \mathrm{Fe}, 0.17 \%$ $\mathrm{Mn}, 0.5 \% \mathrm{Si}, 0.2 \% \mathrm{Cu}, 0.25 \% \mathrm{Zn}$, and balance $\mathrm{Al}$ ) with a dimension of $20 \times 20 \times 4 \mathrm{~mm}^{3}$ were used as substrates. The aluminum plates were ground and polished using waterproof abrasive papers, ultrasonically degreased in acetone, and cleaned with distilled water. The PEO process was carried out under $200 \mathrm{KW}$ bi-polar pulsed power supply (JHMAO200H, Golden Arc Green Protection Technology Development Co. Ltd., Beijing, China) with the frequency of $175 \mathrm{~Hz}$ and duty cycle of $30 \%$. The schematic diagram of the current-voltage waveform is shown in Figure 1. The ancillary devices included a stainless cooling pipe, an electromagnetic stirrer, and electrolytic cell. The two different solutions were used in the PEO process: (1) $20 \mathrm{~g} / \mathrm{L} \mathrm{Na}_{3} \mathrm{PO}_{4} \cdot 12 \mathrm{H}_{2} \mathrm{O}, 1 \mathrm{~g} / \mathrm{L} \mathrm{KOH}$ with $\mathrm{pH}$ about 12.44 ; (2) $15 \mathrm{~g} / \mathrm{L}$ $\mathrm{Na}_{2} \mathrm{AlO}_{2}, 1 \mathrm{~g} / \mathrm{L} \mathrm{KOH}$ with $\mathrm{pH}$ about 12.51. In the $\mathrm{PEO}$ process, $\mathrm{Al}$ alloy plates were treated to different time lengths (30 min and $60 \mathrm{~min}$ ) under the constant anode voltage (500 V) and cathode voltage $(80 \mathrm{~V})$. During the PEO process, the electrolyte temperature was kept below $25^{\circ} \mathrm{C}$ by the water-cooling system and mechanical stirring. The coated samples were washed by distilled water and air dried. The PEO coatings prepared at different treating times of $30 \mathrm{~min}$ and $60 \mathrm{~min}$ in phosphate and aluminate electrolyte were denoted as P30, $\mathrm{P} 60, \mathrm{Al} 30$, and Al60, respectively, in the following text.

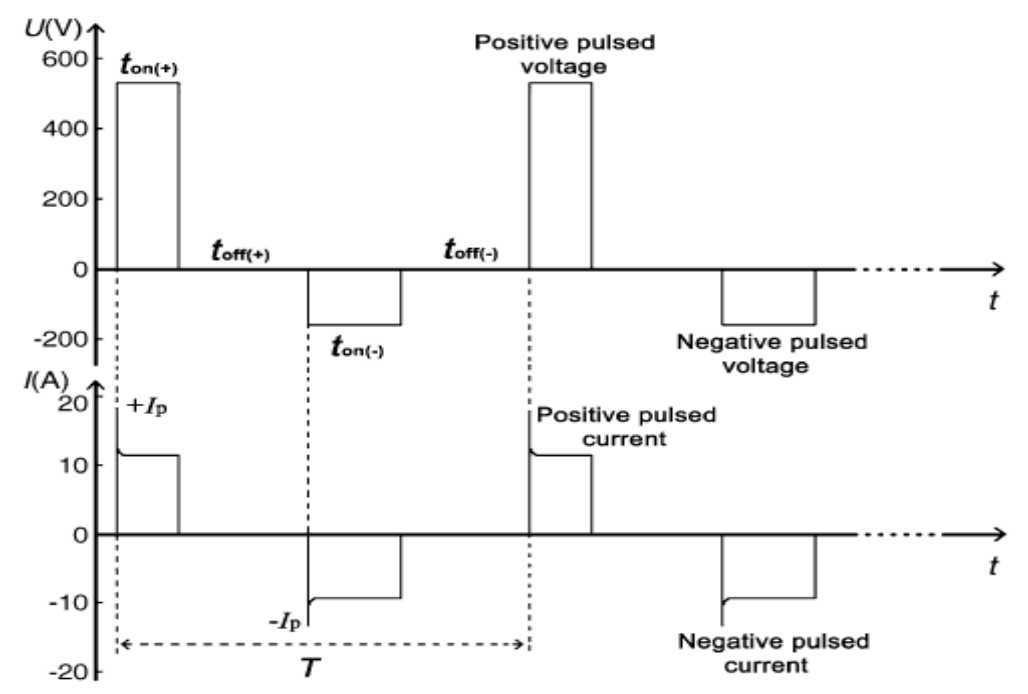

Figure 1. The schematic drawing of the current-voltage waveform in the process of power supply operation. 


\subsection{Surface Characterization of the Coatings}

A scanning electron microscope (SEM, JEOL, Tokyo, Japan, JSM-5601LV) was employed to observe the morphologies of the surface and cross-section of the PEO coatings. The element distribution was studied using energy-dispersive X-ray spectrometer (EDS, Oxford Instruments, Oxon, England, X-Max ${ }^{\mathrm{N}}$ 80). X-ray photoelectron spectroscopy (XPS, ThermoFisher Scientific, Waltham, MA, USA, ESCALAB 250Xi) as a surface analysis technique, equipped with a standard $\mathrm{Al} \mathrm{Ka}$ radiation $(1486.6 \mathrm{eV})$, was used to mensurate the surface composition. The phase composition was analyzed by X-ray diffractometer (XRD, Rigaku, Tokyo, Japan, D/Max-2400) using $\mathrm{Cu} \mathrm{K} \alpha$ radiation from $20^{\circ}$ to $80^{\circ}$. The thickness of the PEO coatings was measured by a digital coating thickness gauge (Elektro Physik, Köln, Germany, Mini-test 1100).

The hardness was measured on a micro-hardness tester (Hengyi Science and Technology Corporation, Shanghai, China, MH-5-VM) with a load of $500 \mathrm{~g}$, pressing $10 \mathrm{~s}$ and holding $5 \mathrm{~s}$. The friction coefficient was performed using a UMT-TriboLab (Bruker, Billerica, MA, USA) reciprocating friction and wear tester in a ball-on-disk contact configuration with the $\mathrm{Si}_{3} \mathrm{~N}_{4}$ ball as the grinding material. The applied loads ranged from $5 \mathrm{~N}, 7 \mathrm{~N}$, to $10 \mathrm{~N}$ at a frequency of $5 \mathrm{~Hz}$ with a reciprocating stroke of $10 \mathrm{~mm}$. The testing time was set to $1800 \mathrm{~s}$ with room temperature at $25^{\circ} \mathrm{C}$ and relative humidity at $30 \%$.

The potentiodynamic polarization of the samples acidic $5 \mathrm{wt} \% \mathrm{NaCl}$ solution $(\mathrm{pH}=3.1-3.3$, we added an amount of glacial acetic acid to the salt solution to ensure that the $\mathrm{pH}$ is between 3.1 and 3.3; see the following text.) were measured by an Autolab PGSTAT302N electrochemical workstation, employing a three-electrode configuration, with the samples as the work electrode, an $\mathrm{Ag} / \mathrm{AgCl}$ electrode as the reference electrode, and a platinum foil as the counter electrode, respectively. The potentiodynamic polarization tests were scanned from -0.85 to $0.85 \mathrm{~V}$ at a scanning rate of $0.01 \mathrm{mV} / \mathrm{s}$ with the reference to the open circuit potential (OCP).

The anti-corrosion property tests were carried out on the salt spray tester in accordance with the standard ISO 9227-2006 with acidic $5 \mathrm{wt} \% \mathrm{NaCl}$ solution $(\mathrm{pH}=3.1-3.3)$. The samples were placed $45^{\circ}$, their surface states were recorded every $24 \mathrm{~h}$, and the surface changes were recorded by a digital camera. In order to ensure the reproducibility, three specimens for each coating were used in the acid salt spray tests.

\section{Results and Discussions}

\subsection{Morphologies of the Coatings}

Figure 2 displays the surface morphologies of the PEO coatings prepared from phosphate and aluminate electrolytes. It can be seen from the figure that there are micro-pores, pancake-like structures, and micro-cracks on the surface of the coatings. However, the electrolyte composition has a great effect on the surface morphology. For the coating formed in the phosphate electrolyte, as can be seen from the Figure 2a, many irregular pores and small cracks uniformly distribute on the P30 coating surface, and most of the pancakes show an overlapping state on the P60 coating (Figure 2b). The formation of micropores can be attributed to the residual plasma discharge channels, and the pancake-like structures are caused by molten oxide ejected from the discharge channels owing to the rapid solidification under the cooling electrolyte. In the aluminate electrolyte, a dense surface with clustered particles and micro-cracks are obtained, yet some micro-pores also distribute around the pancakes, as shown in Figure 2c,d.

In addition, the surface characteristics of PEO coatings also change observably with treating time. For $30 \mathrm{~min}$ treatment, the PEO coatings exhibit porous and flat structures, as shown in Figure 2a,c. When the treatment time increases to $60 \mathrm{~min}$, the pancake structures with diameters more than $15 \mu \mathrm{m}$ and micro-cracks appear on the surface. The surface of the P60 coating is compact and uniform (Figure 2b), while there are a few more clustered particles around the pancake on the surface of the Al60 coating (Figure 2d). It should be noted that each pancake has a closed pore in the center, which is closely relevant to the gas bubbles and the plasma discharge during the PEO process. Obviously, the surface 
morphology of the P60 and A160 coatings gradually becomes rough and compact, and the number of micro-cracks also increases accordingly. The formation of micro-cracks could be caused by thermal stress on the solidification process of the molten oxide and the different phase expansion coefficients of the coating $[27,28]$.
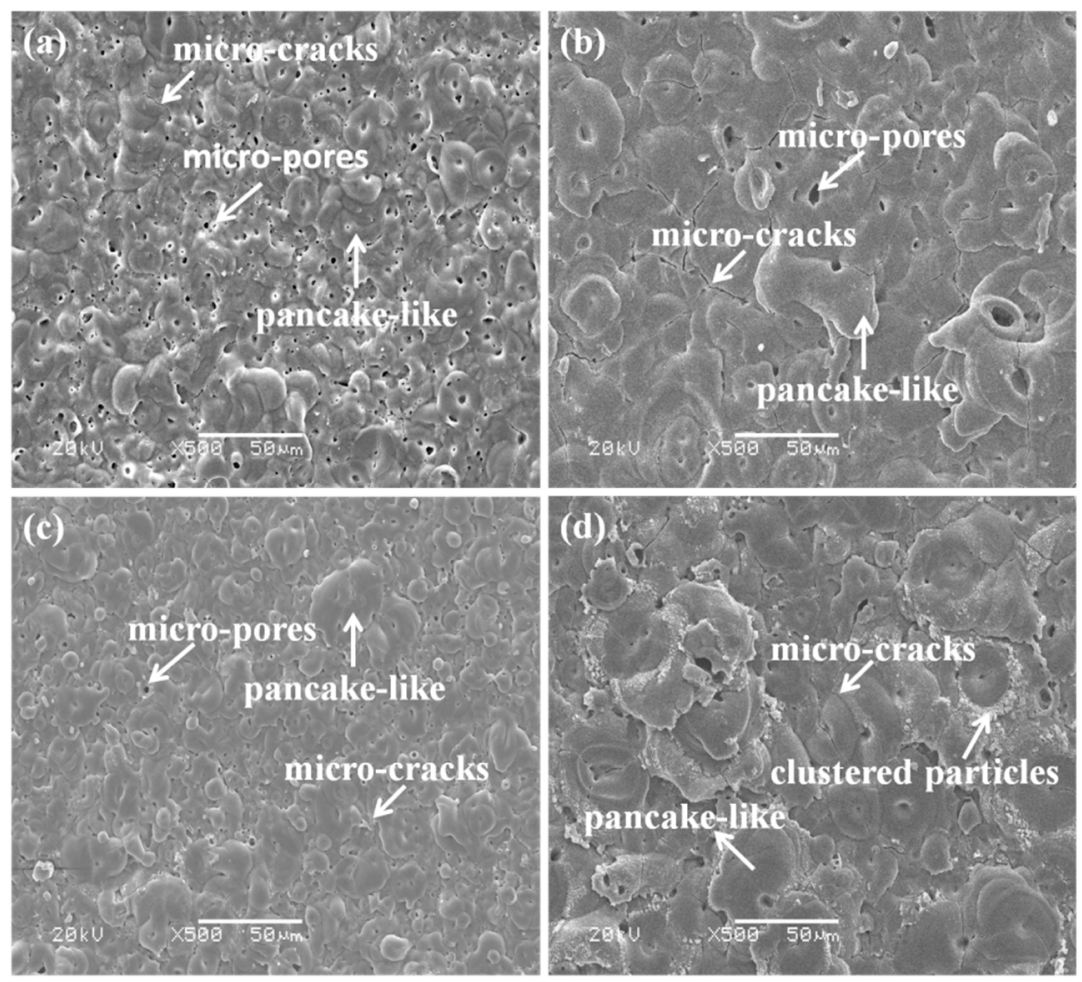

Figure 2. SEM morphologies of the surface coatings prepared from different electrolytes with different treating time: (a,b) P30 and P60 coatings; (c,d) Al30 and Al60 coatings.

\subsection{Cross-Sectional Morphologies and Elemental Distributions of the Coatings}

Figure 3 shows the cross-sectional morphologies and elemental distributions of the PEO coating prepared in phosphate and aluminate electrolytes for different time points. The average thicknesses of the P30, Al30, P60 and Al60 coatings are $\approx 21 \mu \mathrm{m}, \approx 22 \mu \mathrm{m}$, $\approx 31 \mu \mathrm{m}$, and $\approx 32 \mu \mathrm{m}$, respectively. As shown in Figure 3a, the P30 coating shows a bi-layered structure. The outer layer of the PEO coatings has a number of pores, while the inner layer is relative dense with a thickness of $\approx 3 \mu \mathrm{m}$ at the $\mathrm{Al}$ alloy substrate and PEO coating interface. For the Al30 coating, it is relatively dense, and there are no pores in the coating, as shown in Figure 3c. With the treating time prolonged, there is a little change in the structure of the coating. For the P60 coating, the size of pores is bigger and the thickness of the inner layer increases to 5-10 $\mu \mathrm{m}$ (Figure 3b). However, the Al60 coating shows a compact single-layered coating structure. The corresponding EDS elemental mappings shown in Figure 3e-g indicate that there is obvious enrichment of $\mathrm{P}$ element in the denser inner layer of the P60 coating, while the porous outer layer is almost completely composed of $\mathrm{Al}$ and $\mathrm{O}$ elements. Interestingly, the $\mathrm{P}$ element mainly distributes at the substrate/coating interface, which forms a phosphorus-rich dense barrier layer. The Al60 coating exhibits a uniform distribution of $\mathrm{Al}$ and $\mathrm{O}$ elements along the entire coating, as show in Figure 3h,i. 

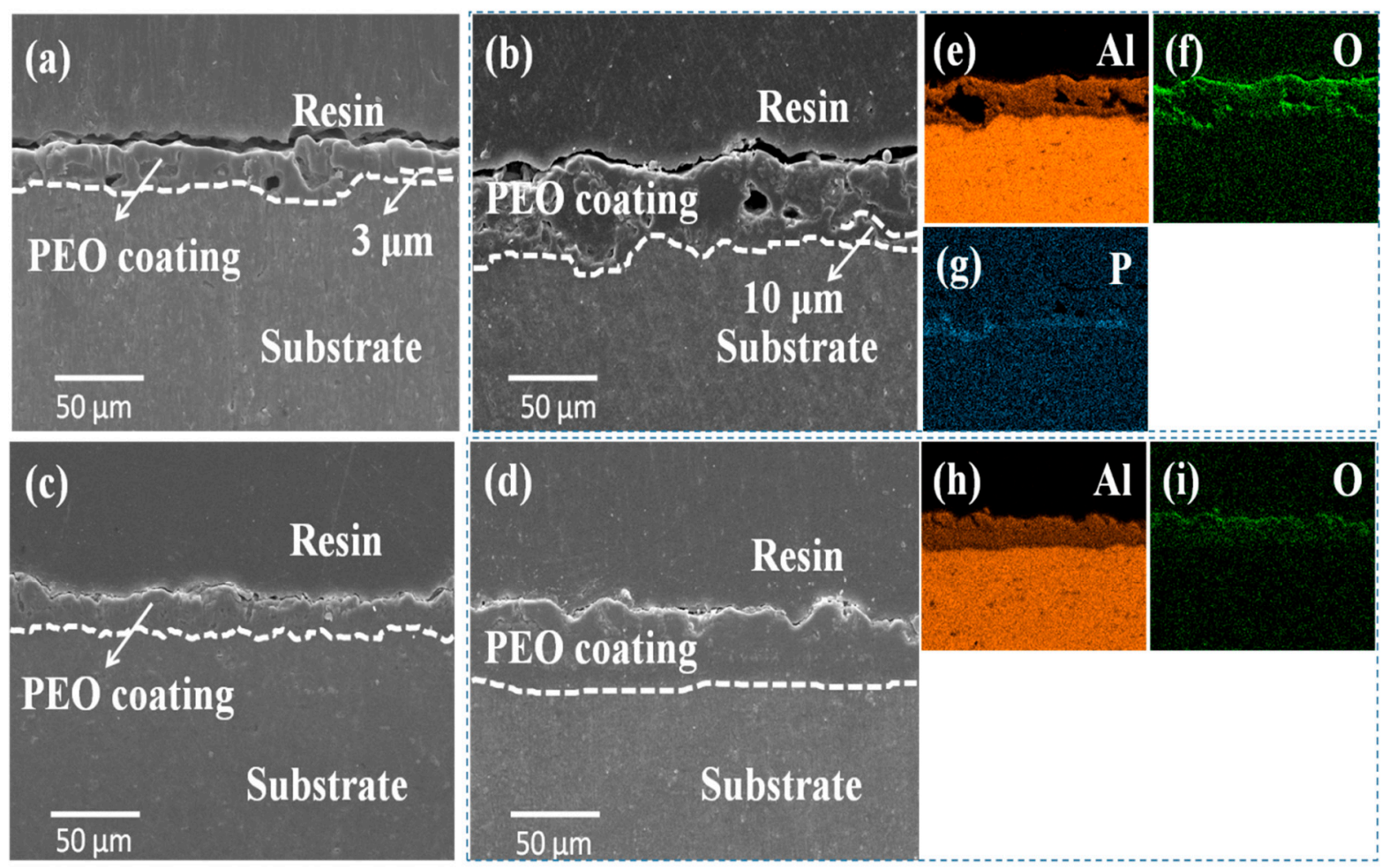

Figure 3. Cross-sectional SEM morphologies of the surface coatings prepared from different electrolytes with different treating time: (a,b) P30 and P60 coatings; (c,d) Al30 and Al60 coatings; (e-g) the EDS elemental mappings of P60 coating; (h,i) the EDS elemental mappings of Al60 coating.

\subsection{Phase and Chemical Composition of the Coatings}

Figure 4 presents the XRD patterns of PEO coatings prepared from phosphate and aluminate electrolytes at different time points. It can be seen that the characteristic diffraction peaks corresponding to $\alpha-\mathrm{Al}_{2} \mathrm{O}_{3}$ (JCPDS NO. 01-1243), $\gamma-\mathrm{Al}_{2} \mathrm{O}_{3}$ (JCPDS NO. 10-0425), and $\mathrm{Al}$ are clearly identified for the P30, Al30, P60, and Al60 coatings. In addition, there is a hump between $24^{\circ}$ and $42^{\circ}$ in $2 \theta$ for the P30 and P60 coatings, indicating the presence of amorphous compounds. It is well known that alumina phases are different not only in their structure but also in the properties. Usually, the $\alpha-\mathrm{Al}_{2} \mathrm{O}_{3}$ phase exhibits higher hardness compared with the $\gamma-\mathrm{Al}_{2} \mathrm{O}_{3}$ phase. The $\gamma-\mathrm{Al}_{2} \mathrm{O}_{3}$ to $\alpha-\mathrm{Al}_{2} \mathrm{O}_{3}$ transition occurs at temperatures above $950{ }^{\circ} \mathrm{C}$. During the PEO process, the temperature of the spark discharge can reach $3000{ }^{\circ} \mathrm{C}$ or higher, which promotes the transformation of the $\gamma-\mathrm{Al}_{2} \mathrm{O}_{3}$ phase to the $\alpha-\mathrm{Al}_{2} \mathrm{O}_{3}$ phase. Furthermore, the low thermal conductivity of aluminium oxide results in the underlayer of the coatings to become heated and also facilitates the further transformation of the initially formed metastable $\gamma-\mathrm{Al}_{2} \mathrm{O}_{3}$ phase into the stable $\alpha-\mathrm{Al}_{2} \mathrm{O}_{3}$ phase. The relative content of the $\alpha-\mathrm{Al}_{2} \mathrm{O}_{3}$ and $\gamma-\mathrm{Al}_{2} \mathrm{O}_{3}$ phases in PEO coatings can be calculated from the integrated intensities of the $\alpha-\mathrm{Al}_{2} \mathrm{O}_{3}$ (113) and $\gamma-\mathrm{Al}_{2} \mathrm{O}_{3}$ (400) peaks, I $\alpha$ and $\mathrm{I} \gamma$, respectively $[17,29-31]$. The ratios of $\mathrm{I} \alpha / \mathrm{I} \gamma$ for the P30, Al30, P60, and Al60 coating are $0.01,0.47,0.12$, and 1.64 , respectively. Therefore, the relative content of $\alpha-\mathrm{Al}_{2} \mathrm{O}_{3}$ is significantly increased for the PEO coatings with increasing treatment time, and the ratio of $\mathrm{I} \alpha / \mathrm{I} \gamma$ of aluminate PEO coatings is higher than that of phosphate PEO coatings at the same treatment time, indicating that the aluminate electrolyte more easily forms the $\alpha-\mathrm{Al}_{2} \mathrm{O}_{3}$ phase in the PEO coatings than the phosphate electrolyte. 


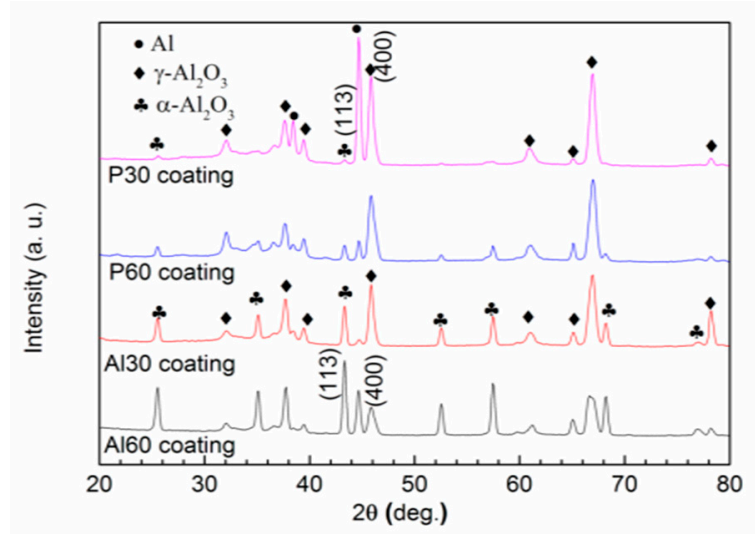

Figure 4. XRD patterns of the surface coatings prepared from different electrolytes with different treating time.

Figure 5a shows the XPS full-survey spectra of the P60 and Al60 coatings. The P60 coating contains $\mathrm{Al}, \mathrm{O}$, and $\mathrm{P}$ elements, and the $\mathrm{Al} 60$ coating consists of $\mathrm{Al}$ and $\mathrm{O}$ elements, which are identical with the results of EDS analyses. The C element is the impurities on surface of the coating. The specific $\mathrm{Al} 2 \mathrm{p}$ spectra show peaks at binding energies of $74.8 \mathrm{eV}$ and $74.3 \mathrm{eV}$ that correspond to $\mathrm{Al}_{2} \mathrm{O}_{3}$, as shown in Figure $5 \mathrm{~b}[12,32]$. Furthermore, the peaks of $\mathrm{PO}_{3}{ }^{-}$with binding energy at $134.5 \mathrm{eV}$ for P30 and P60 coatings illustrate that metaphosphate presents on the P60 coating, as shown in Figure 5c [33], which indicates that the hump in the XRD patterns of the P30 and P60 coatings are attributed to the presence of amorphous metaphosphate.
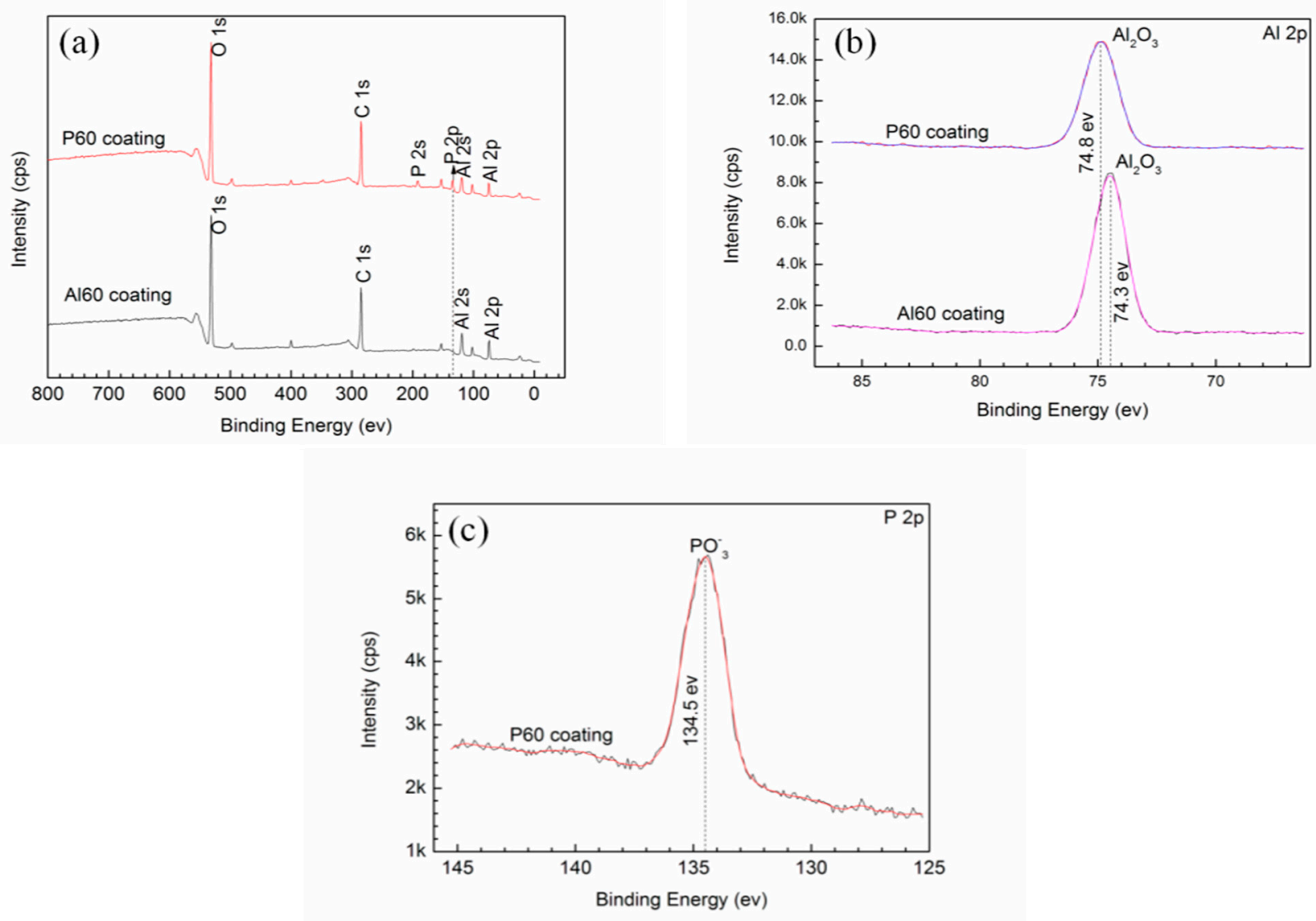

Figure 5. XPS spectra of the surface coatings prepared from different electrolytes with different treating time. (a) The surveys of the A60 and P60 coatings, the high-resulotion spectra of (b) Al 2p and (c) P 2p. 


\subsection{Micro-Hardness of the Coatings}

Figure 6 shows the micro-hardness of $6061 \mathrm{Al}$ alloy substrate and PEO coatings obtained from different electrolytes with different treating time. As we can see from the graph, the micro-hardness of $6061 \mathrm{Al}$ alloy substrate is about $155 \mathrm{HV}$. For the PEO treatment, the micro-hardness is significantly enhanced. The Al60 coating has the largest average hardness of $1300 \mathrm{HV}$, which is 8 times that of the $6061 \mathrm{Al}$ alloy substrate. Nevertheless, the micro-hardness of the P30 coating is relatively low and about $700 \mathrm{HV}$, which is 4 times that of the substrate. In addition, it can be deduced from Figure 5 that the micro-hardness of PEO coatings grown in the same electrolyte increases with the increase of the treatment time; that is, the greater the thickness of the PEO coating, the higher the hardness.

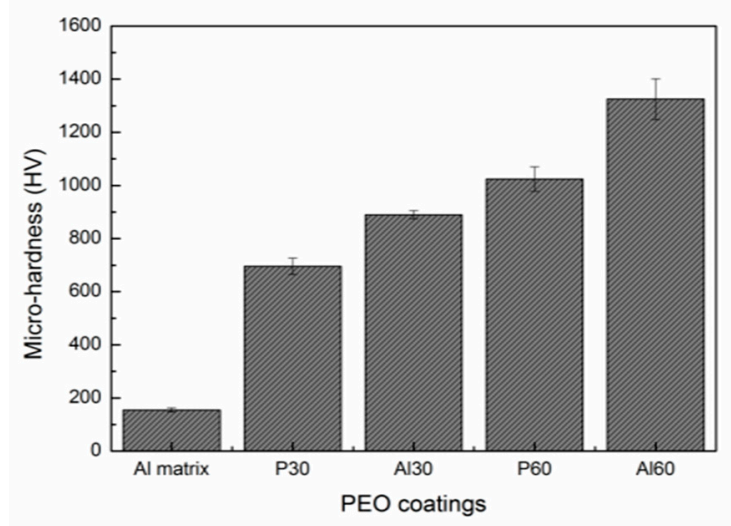

Figure 6. Micro-hardness of $6061 \mathrm{Al}$ alloy substrate and PEO coatings.

It is known that the micro-hardness of the PEO coatings is related to the surface structure and phase composition [28]. On the basis of the SEM results, the P60 and A160 coatings are thicker and denser than the P30 and Al30 coatings. On the other hand, the $X R D$ results shows that the $\mathrm{PEO}$ coatings prepared from aluminate electrolytes with longer treating times have a higher content of $\alpha-\mathrm{Al}_{2} \mathrm{O}_{3}$ phase, which is helpful for improving the hardness.

\subsection{Friction and Wear Properties of the Coatings}

Figure 7 presents the friction curves of P30, Al30, P60, and Al60 coatings at $5 \mathrm{~N}$ loads under dry friction conditions. As we can see from the curves, the friction coefficient of the PEO coatings fluctuates with the sliding time. There is a run-in stage in the friction process, which may be concerned with the irregular surface morphology of the coatings [28]. The run-in stages of all the samples are about $200 \mathrm{~s}$, and the friction coefficient became stable within the range from 0.75 to 0.85 , as observed in Figure 7 . For the P30 coating samples, the friction coefficient increases gradually to 0.78 within $960 \mathrm{~s}$ and then drops suddenly, indicating that the coating has been worn through. For the Al30, P60, and Al60 coatings, they have a relatively high friction coefficient, which may be attributed to the larger shear stress at dry friction conditions and uneven distribution of surface microstructures, as shown in Figure 2. In addition, these PEO coatings still exist after a wear test for $1800 \mathrm{~s}$, indicating that those coatings have excellent wear resistance.

Figure 8 shows the morphologies of a wear track after dry sliding tests under $5 \mathrm{~N}$ load. As we can see from Figure 8a, the P30 coating shows obvious tearing, plastic flow, adhesion, and furrow characteristics, indicating that the P30 coating have been thoroughly worn through. As shown in Figure 8b-d, most of the coating's areas did not appear to have much damage, which indicated the good wear resistance of these coatings (just as the coatings test with loads of $7 \mathrm{~N}, 8 \mathrm{~N}, 9 \mathrm{~N}$, and $10 \mathrm{~N}$ ). The magnified image of morphology is presented on the upper right of Figure $8 \mathrm{~b}-\mathrm{d}$. As we can see from that, the micro-morphologies of the wear track for $\mathrm{Al} 30$ and $\mathrm{P} 60$ coatings exhibit furrows and a small range of exfoliation. This illustrates that the main wear mechanisms of the PEO coatings are abrasive wear and 
fatigue wear. Nevertheless, the furrows and the area of exfoliation for the Al60 coating reduced in size, which is attributed to the lower porosity, higher compactness, and lack of defects in the PEO coatings.

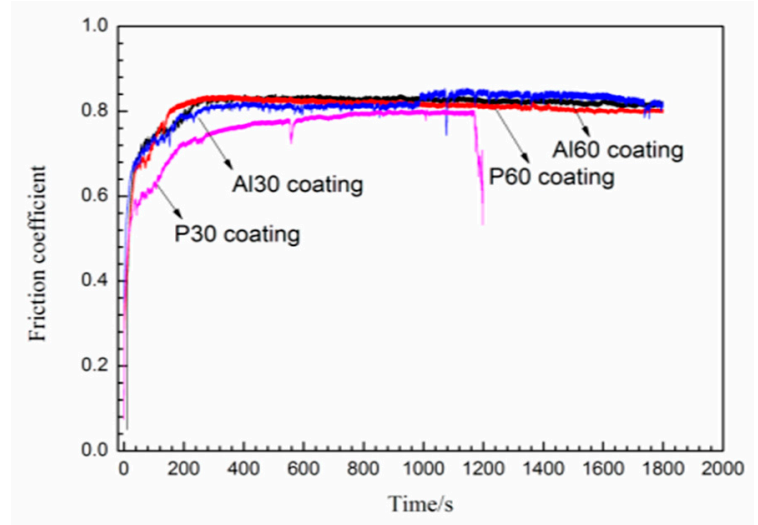

Figure 7. Friction coefficient as a function of sliding time under $5 \mathrm{~N}$ for P30, Al30, P60, and Al60 coating.
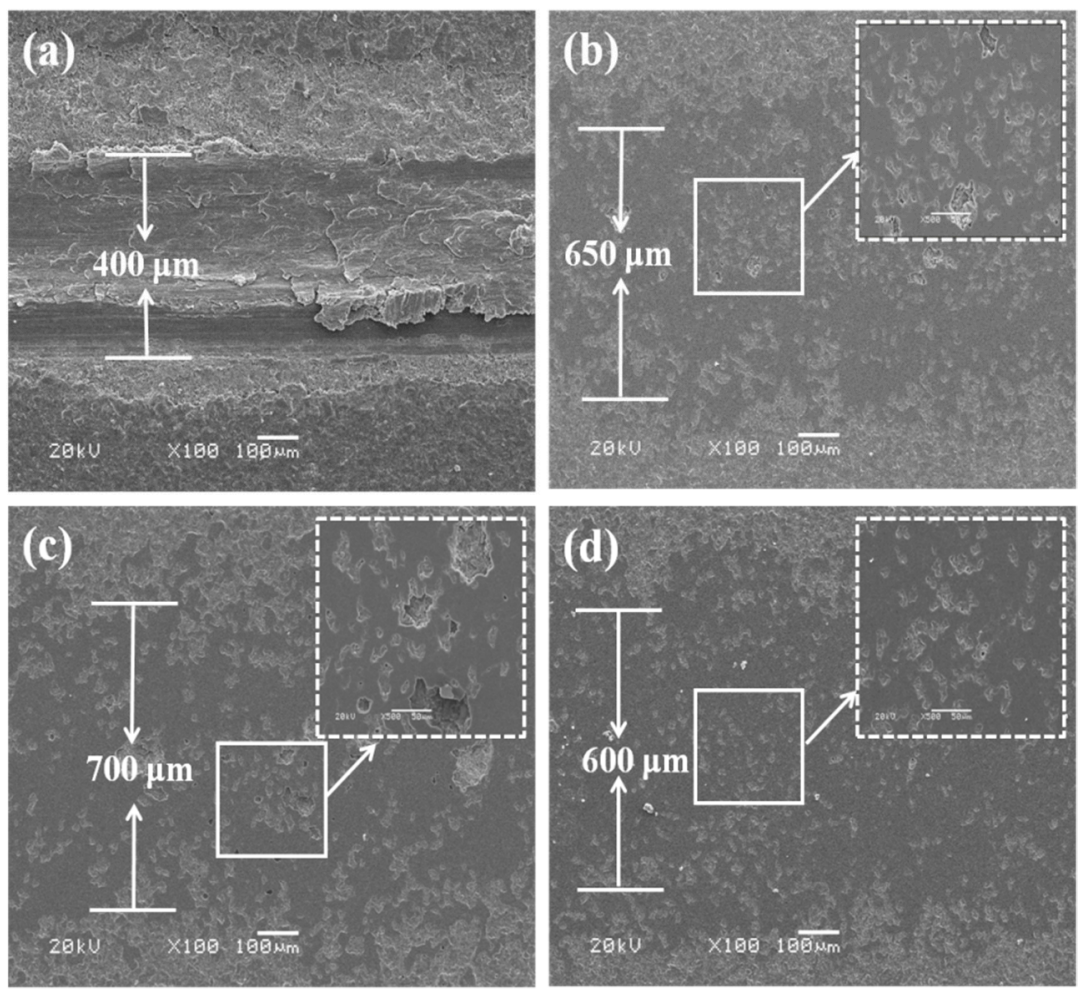

Figure 8. SEM images of wear marks at different coatings surface under dry friction conditions: (a,b) P30 and P60 coatings; (c,d) Al30 and Al60 coatings.

The cross-sectional profiles of the PEO coatings are shown in Figure 9. These profiles are carried out to estimate the wear rate. The summary of the friction and wear test results of the PEO coatings is listed in Table 1 . The wear tracks of the P30 coating are around $29 \mu \mathrm{m}$ in depth and $400 \mu \mathrm{m}$ in width. The wear track depth of the Al30 and P60 coatings are substantially reduced, which register $20 \mu \mathrm{m}$ and $18 \mu \mathrm{m}$. For the Al60 coating, the values of the depth are further reduced than those of the other coatings. Benefitting from the larger thickness and higher ratio of harder compounds, there is an evident improvement of the wear resistance. Based on the wear profiles, the specific wear rates of the P30, $\mathrm{Al30}, \mathrm{P} 60$, and $\mathrm{Al} 60$ at $5 \mathrm{~N}$ loads are $6.46 \times 10^{-4} \mathrm{~mm}^{3} / \mathrm{N} \cdot \mathrm{m}, 1.37 \times 10^{-4} \mathrm{~mm}^{3} / \mathrm{N} \cdot \mathrm{m}$, $1.66 \times 10^{-4} \mathrm{~mm}^{3} / \mathrm{N} \cdot \mathrm{m}$, and $8.24 \times 10^{-5} \mathrm{~mm}^{3} / \mathrm{N} \cdot \mathrm{m}$, respectively. It is deduced that the 
wear rate of the Al60 coating is nearly an order of magnitude lower than that of the P30 coating.

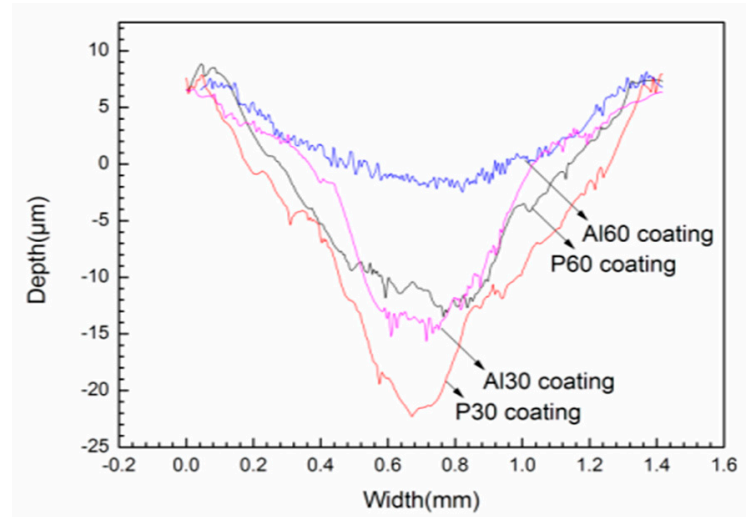

Figure 9. Cross-sectional profiles of wear marks at loads $5 \mathrm{~N}$ under dry friction conditions on the PEO coatings.

Table 1. The average friction coefficients and wear rates of the PEO coatings.

\begin{tabular}{ccccc}
\hline Coatings & $\begin{array}{c}\text { Coefficient of } \\
\text { Friction }\end{array}$ & $\begin{array}{c}\text { Width of Wear } \\
\text { Track }(\boldsymbol{\mu} \mathbf{m})\end{array}$ & $\begin{array}{c}\text { Depth of Wear } \\
\text { Track }(\boldsymbol{\mu m})\end{array}$ & $\begin{array}{c}\text { Wear Rate } \\
\left(\mathbf{m m}^{3} / \mathbf{N} \cdot \mathbf{m}\right)\end{array}$ \\
\hline P30 & $0.78 \pm 0.01$ & 400 & 29 & $6.46 \times 10^{-4}$ \\
P60 & $0.81 \pm 0.01$ & 650 & 18 & $1.66 \times 10^{-4}$ \\
A130 & $0.83 \pm 0.02$ & 700 & 20 & $1.37 \times 10^{-4}$ \\
A160 & $0.82 \pm 0.01$ & 600 & 8 & $8.24 \times 10^{-5}$ \\
\hline
\end{tabular}

The sliding tests of the PEO coatings at higher load $(7 \mathrm{~N})$ were used to further evaluate the difference of their wear resistance. It is found from Figure 10 that the P30, Al30, and P60 coatings are worn through after $\approx 100 \mathrm{~s}, 340 \mathrm{~s}$, and $440 \mathrm{~s}$ with loads of $7 \mathrm{~N}$, respectively. However, the friction curve of the Al60 coating remains stable during the sliding time of $1800 \mathrm{~s}$, which shows much better wear resistance than other coatings under the load of $7 \mathrm{~N}$. To further evaluate the friction and wear property of the Al60 coating, the loads of $8 \mathrm{~N}, 9 \mathrm{~N}$, and $10 \mathrm{~N}$ are used for the slide test, and the friction coefficient curves are shown in Figure 11. As we can see from that, the Al60 coating shows a stable friction coefficient within the sliding time of $600 \mathrm{~s}$ under $8 \mathrm{~N}$ loads. However, the friction coefficient drops at the sliding time of about $200 \mathrm{~s}$ under $9 \mathrm{~N}$ loads, while the friction curve dramatically decreased on applying a load of $10 \mathrm{~N}$.

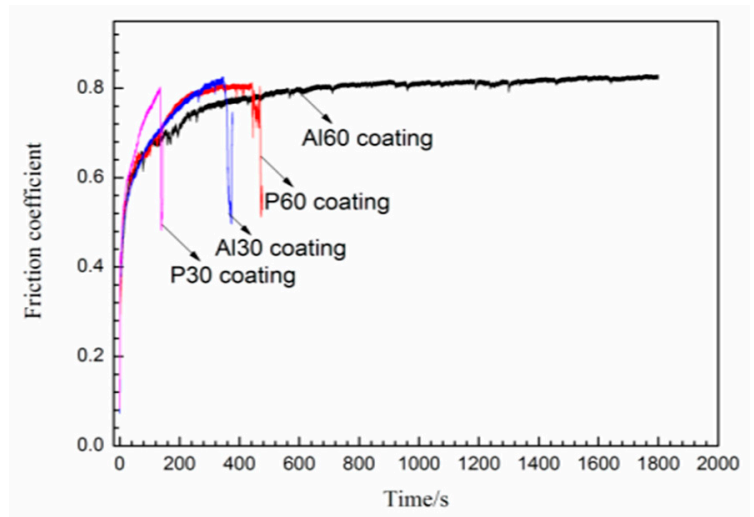

Figure 10. Friction coefficient as a function of sliding time under $7 \mathrm{~N}$ for PEO coatings. 


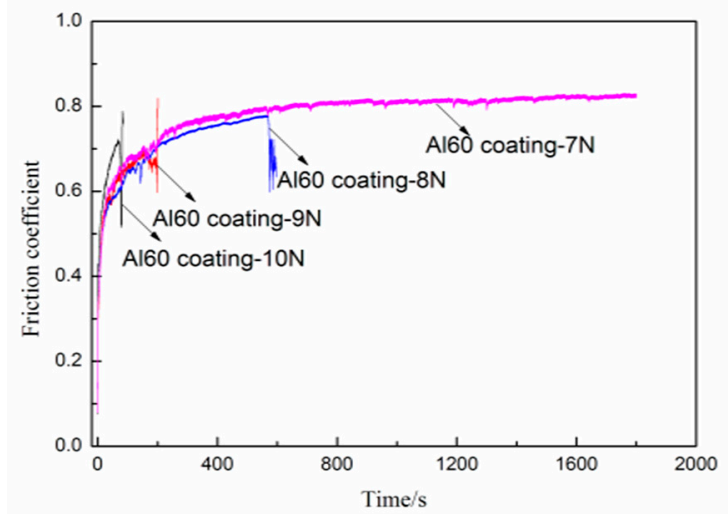

Figure 11. Friction coefficient as a function of sliding time under different loads for Al60 coating.

\subsection{Corrosion Behavior of the PEO Coatings}

Figure 12 displays the potentiodynamic polarization curves that were carried out in the $5 \mathrm{wt} \% \mathrm{NaCl}(\mathrm{pH}=3.1-3.3)$ corrosive media after OCP stabilization. The corrosion potential $\left(\mathrm{E}_{\mathrm{corr}}\right)$ and current density ( $\left.\mathrm{i}_{\text {corr }}\right)$ of the $6061 \mathrm{Al}$ alloy and PEO coatings obtained from Figure 12 are listed in Table 2. As we can see from Figure 12, the PEO coatings have much lower $\mathrm{i}_{\text {corr }}$ and more positive $\mathrm{E}_{\text {corr }}$ than the $\mathrm{Al}$ alloy substrate, indicating that the $\mathrm{PEO}$ coatings improve the corrosion resistance of $\mathrm{Al}$ alloy. For the $\mathrm{PEO}$ coatings, the $\mathrm{E}_{\text {corr }}$ has a positive shift, and the $i_{\text {corr }}$ decreases with the treatment time increasing. According to Table 2, the P60 coating shows the lowest corrosion current density $\left(1.09 \times 10^{-7} \mathrm{~A} \cdot \mathrm{cm}^{-2}\right)$. Therefore, the P60 coating exhibits the best corrosion resistance compared to those other coatings in acidic solution according to the potentiodynamic polarization results.

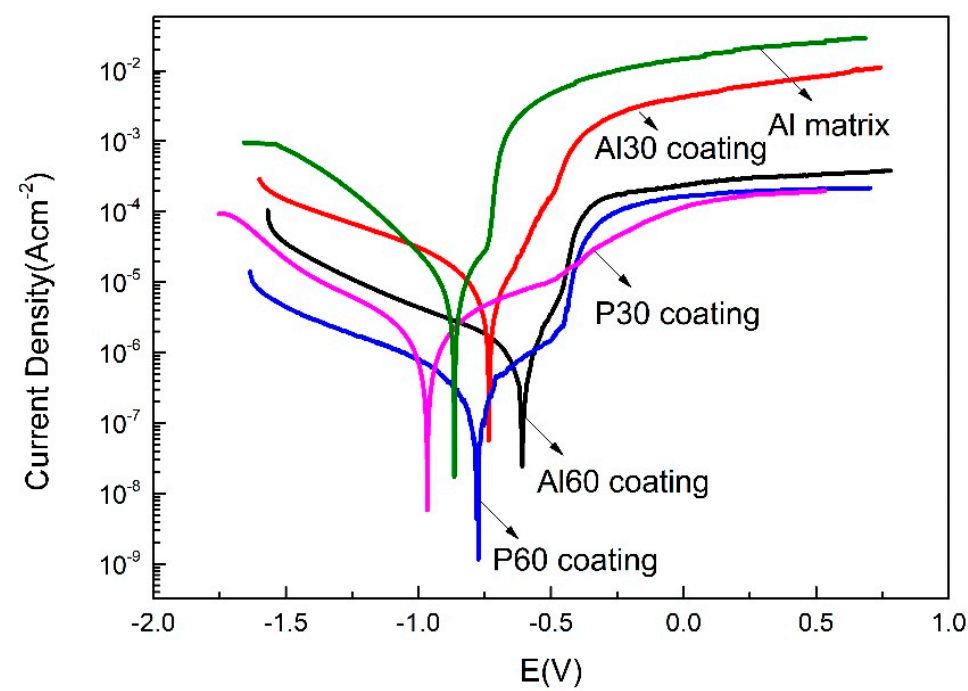

Figure 12. Potentiodynamic polarization curves in $5 \mathrm{wt} \% \mathrm{NaCl}$ solution $(\mathrm{pH}=3.1-3.3)$ for uncoated and PEO coated.

Table 2. Fitting results of potentiodynamic polarization curves in $5 \mathrm{wt} \% \mathrm{NaCl}$ solution $(\mathrm{pH}=3.1-3.3)$ for uncoated and PEO coated.

\begin{tabular}{ccc}
\hline Sample & $\mathbf{E}_{\text {corr }}(\mathbf{V}$ vs. AgCl) & $\mathbf{i}_{\text {corr }}\left(\mathbf{A} \cdot \mathbf{c m}^{-\mathbf{2}}\right)$ \\
\hline Al alloy & -0.874 & $9.28 \times 10^{-6}$ \\
P30 coating & -0.964 & $1.22 \times 10^{-6}$ \\
Al30 coating & -0.739 & $4.77 \times 10^{-6}$ \\
P60 coating & -0.784 & $1.09 \times 10^{-7}$ \\
Al60 coating & -0.610 & $5.61 \times 10^{-7}$ \\
\hline
\end{tabular}


Figure 13 presents the optical photographs of $6061 \mathrm{Al}$ alloy, P60 coating, and Al60 coating after the acid salt spray test for $696 \mathrm{~h}$. As we can see from Figure 13a-c, the Al alloy is severely corroded and completely covered by corrosion products after $72 \mathrm{~h}$ of testing, indicating that the $\mathrm{Al}$ alloy has low corrosion resistance in an acidic corrosion environment. The $\mathrm{P} 60$ coating and $\mathrm{Al} 60$ coating show excellent corrosion resistance than the $6061 \mathrm{Al}$ alloy. For the P60 coating, no corrosion can be observed from Figure 13d-f after a $696 \mathrm{~h}$ acid-salt-spray test. In the case of the Al60 coating, a few corrosion pits appear on the surface after $216 \mathrm{~h}$ tests. Severe corrosion occurred after $696 \mathrm{~h}$, suggesting that the Al60 coating lost the protection to $\mathrm{Al}$ alloy from corrosion to some extent, as shown in Figure $13 \mathrm{~g}-\mathrm{i}$. The results indicate that the phosphate PEO coating shows much better corrosion protection performance in an acidic corrosion environment than the aluminate PEO coating.
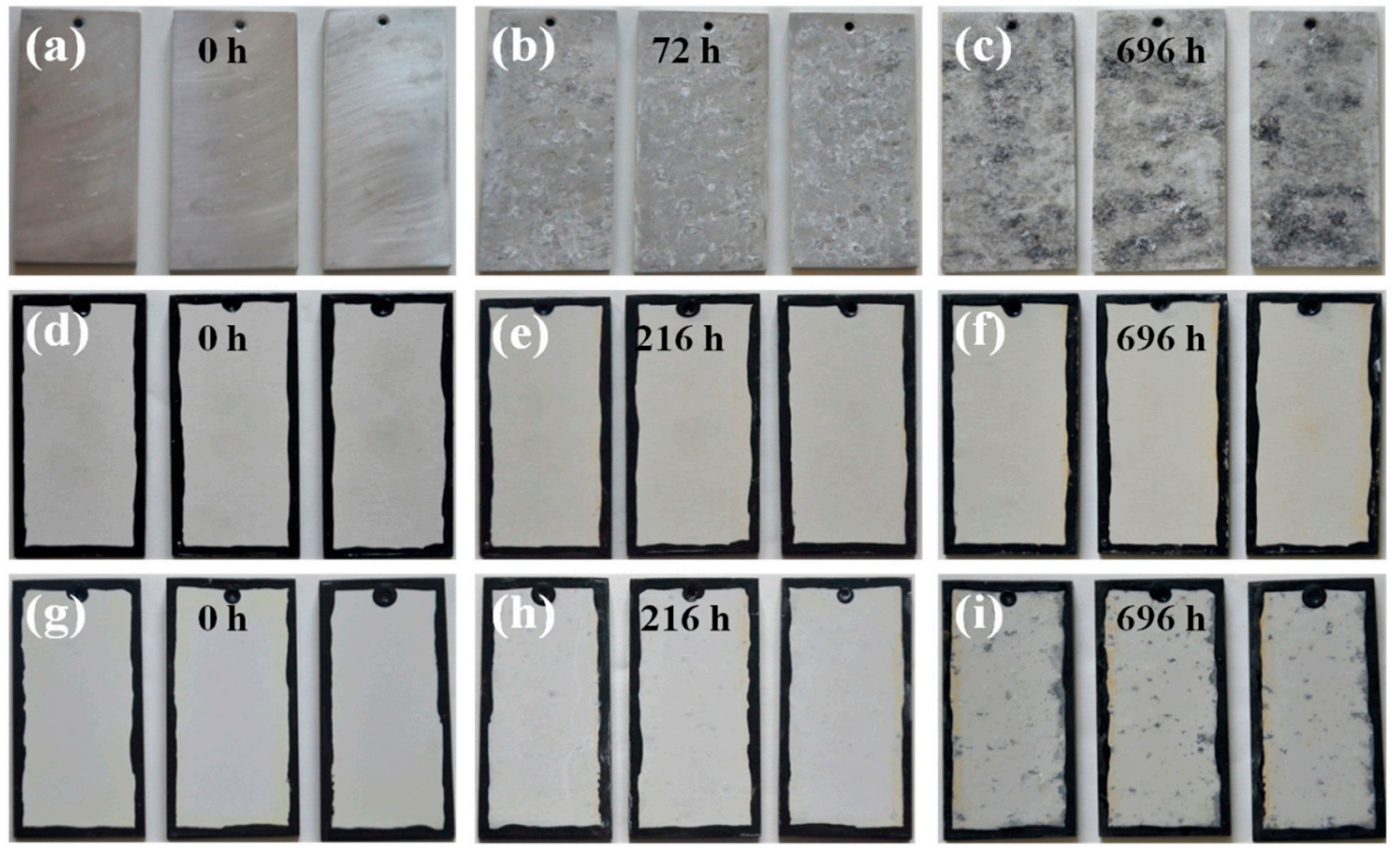

Figure 13. Optical appearance of the PEO coatings after the anti-corrosion property tests in acid $5 \mathrm{wt} \% \mathrm{NaCl}$ solution $(\mathrm{pH}=3.1-3.3)$ for $696 \mathrm{~h}$ : (a-c) $6061 \mathrm{Al}$ alloy; (d-f) P60; (g-i) Al60.

These performance characteristics may be connected with the microstructure and composition of the PEO coatings. The P60 coating has a bi-layered structure. Although there are pores in the outer layer, the perforated pores have been blocked by that which solidified under the cooling electrolyte effection, resulting in the pores not coming through the coating [34]. Furthermore, the inner layer with the thickness of $\approx 10 \mu \mathrm{m}$ of the substrate/coating interface is relatively dense, and a phosphorus-rich oxide was characterized, as shown in Figure 6. This dense layer played a vital role in the inhibition of the penetration of the acid corrosive medium. When the acid corrosive medium penetrated into the coating, the loose layer can act as a barrier to prevent the entry and decrease the rate of diffusion of acid corrosive medium [35]. Moreover, the amorphous phosphorus-rich oxide will improve the acid anti-corrosion properties of the PEO coatings, while the inner layer of the Al60 coating was mainly composed of aluminum oxide. The crystal boundaries or microcracks of the aluminum oxide are easily eroded by acid corrosive medium, which create the path of access by acid corrosive medium, resulting in the deterioration of the corrosion resistance. 


\section{Conclusions}

PEO coatings were fabricated on 6061 aluminum alloy in phosphate and aluminate electrolytes, respectively, and the wear and acid corrosion resistance were compared. The conclusions are as follows:

1. $\gamma-\mathrm{Al}_{2} \mathrm{O}_{3}$ and $\alpha-\mathrm{Al}_{2} \mathrm{O}_{3}$ are the main crystal phases of the PEO coatings, accompanied by a small amount amorphous of phosphorus-rich oxide formed in phosphate electrolyte. With the increase of PEO treating time, the ratios of $\mathrm{I} \alpha / \mathrm{I} \gamma$ increased and the surface hardness increased.

2. The single-layered coatings formed in the aluminate electrolyte exhibit more desirable wear resistance than that in the phosphate electrolyte, which is relatively high $\alpha-\mathrm{Al}_{2} \mathrm{O}_{3}$ content.

3. The bi-layered coatings formed in the phosphate electrolyte have better excellent acid corrosion resistance, which is attributed to the dense phosphorus-rich oxide of the inner layer.

Author Contributions: Project administration, H.X. and J.L.; Methodology, H.X., J.L. and Z.P. Writing—original draft, Z.P.; Supervision, H.X., J.L. and S.L.; Writing—review and editing, J.L., S.L. and Y.Q.; Investigation, Y.Q.; Visualization, Z.P.; Data curation, Z.P. and S.L.; Funding acquisition, J.L. All authors have read and agreed to the published version of the manuscript.

Funding: The financial support from the National Natural Science Foundation of China (Grant No. 52071325) is acknowledged.

Institutional Review Board Statement: Not applicable.

Informed Consent Statement: Not applicable.

Data Availability Statement: The data presented in this study are available on request from the corresponding author.

Conflicts of Interest: There is no conflict of interest.

\section{References}

1. Wang, Z.; Qu, R.T.; Scudino, S.; Sun, B.A.; Prashanth, K.G.; Louzguine-Luzgin, D.V.; Chen, M.W.; Zhang, Z.F.; Eckert, J. Hybrid nanostructured aluminum alloy with super-high strength. NPG Asia Mater. 2015, 7, 229. [CrossRef]

2. Park, G.H.; Kim, J.T.; Park, H.J.; Kim, Y.S.; Jeong, H.J.; Lee, N.; Seo, Y.; Suh, J.Y.; Son, H.T.; Wang, W.M.; et al. Development of lightweight Mg-Li-Al alloys with high specifific strength. J. Alloys Compd. 2016, 680, 116-120. [CrossRef]

3. Shin, J.; Kim, T.; Kim, D.E.; Kim, D.; Kim, K. Castability and mechanical properties of new 7xxx aluminum alloys for automotive chassis/body applications. J. Alloys Compd. 2017, 698, 577-590. [CrossRef]

4. Torre, A.D.L.; Afeltra, U.; Gomez-Esparza, C.D.; Camarillo-Cisneros, J.; Martinez-Sanchez, J. Grain refiner effect on the microstructure and mechanical properties of the A356 automotive wheels. J. Mater. Eng. Perform. 2014, 23, 581-587. [CrossRef]

5. Yerokhin, A.L.; Snizhko, L.O.; Gurevina, N.L.; Leyland, A.; Pilkington, A.; Matthews, A. Spatial characteristics of discharge phenomena in plasma electrolytic oxidation of aluminium alloy. Surf. Coat. Technol. 2004, 177, 779-783. [CrossRef]

6. Wang, J.H.; Du, M.H.; Han, F.Z.; Yang, J. Effects of the ratio of anodic and cathodic currents on the characteristics of micro-arc oxidation ceramic coatings on Al-alloys. Appl. Surf. Sci. 2014, 292, 658-664. [CrossRef]

7. Abreu, C.M.; Cristobal, M.J.; Figueroa, R.; Pena, G. Wear and corrosion performance of two different tempers (T6 and T73) of AA7075 aluminium alloy after nitrogen implantation. Appl. Surf. Sci. 2015, 327, 51-61. [CrossRef]

8. Yin, B.; Peng, Z.J.; Liang, J.; Jin, K.J.; Zhu, S.Y.; Yang, J.; Qiao, Z.H. Tribological behavior and mechanism of self-lubricating wear-resistant composite coatings fabricated by one-step plasma electrolytic oxidation. Tribol. Int. 2016, 97, 97-107. [CrossRef]

9. Tsukamoto, T.; Ogino, T. Control of the spatial distribution of porous alumina micro-domes formed during anodic oxidation. Electrochim. Acta 2009, 54, 4712-4717. [CrossRef]

10. Chen, R.; Iwabuchi, A.; Shimizu, T. The effect of a T6 heat treatment on the fretting wear of a SiC particle-reinforced A356 aluminum alloy matrix composite. Wear 2000, 238, 110-119. [CrossRef]

11. Bolelli, G.; Bonferroni, B.; Coletta, G.; Lusvarghi, L.; Pitacco, F. Wear and corrosion behaviour of HVOF WCe-CoCr/CVD DLC hybrid coating systems deposited onto aluminium substrate. Surf. Coat. Technol. 2011, 205, 4211-4220. [CrossRef]

12. Wang, S.X.; Liu, X.H.; Yin, X.L.; Du, N. Influence of electrolyte components on the microstructure and growth mechanism of plasma electrolytic oxidation coatings on 1060 aluminum alloy. Surf. Coat. Technol. 2020, 381, 125-214. [CrossRef]

13. Li, Q.B.; Liang, J.; Liu, B.X.; Peng, Z.J.; Wang, Q. Effects of cathodic voltages on structure and wear resistance of plasma electrolytic oxidation coatings formed on aluminium alloy. Appl. Surf. Sci. 2014, 297, 176-181. [CrossRef] 
14. Fadaee, H.; Javidi, M. Investigation on the corrosion behaviour and microstructure of 2024-T3 Al alloy treated via plasma electrolytic oxidation. J. Alloys Compd. 2014, 604, 36-42. [CrossRef]

15. Monfort, F.; Berkani, A.; Matykina, E.; Skeldon, P.; Thompson, G.E.; Habazaki, H.; Shimizu, K. Development of anodic coatings on aluminium under sparking conditions in silicate electrolyte. Corros. Sci. 2007, 49, 672-693. [CrossRef]

16. Wang, D.D.; Liu, X.T.; Wu, Y.K.; Han, H.P.; Shen, D.J. Evolution process of the plasma electrolytic oxidation (PEO) coating formed on aluminum in an alkaline sodium hexametaphosphate $\left(\left(\mathrm{NaPO}_{3}\right)_{6}\right)$ electrolyte. J. Alloys Compd. 2019, 798, 129-143. [CrossRef]

17. Xie, H.J.; Cheng, Y.L.; Li, S.X.; Cao, J.H.; Cao, L. Wear and corrosion resistant coatings on surface of cast A356 aluminum alloy by plasma electrolytic oxidation in moderately concentrated aluminate electrolytes. Trans. Nonferrous Met. Soc. China 2017, 27, 336-351. [CrossRef]

18. Cheng, Y.L.; Xue, Z.G.; Wang, Q.; Wu, X.Q.; Matykina, E.; Skeldon, P.; Thompson, G.E. New findings on properties of plasma electrolytic oxidation coatings from study of an Al-Cu-Li alloy. Electrochimi. Acta 2013, 107, 358-378. [CrossRef]

19. Lugovskoy, A.; Zinigrad, M.; Kossenko, A.; Kazanski, B. Production of ceramic layers on aluminum alloys by plasma electrolytic oxidation in alkaline silicate electrolytes. Appl. Surf. Sci. 2013, 264, 743-747. [CrossRef]

20. Aliramezani, R.; Raeissi, K.; Santamaria, M.; Hakimizad, A. Characterization and properties of PEO coatings on $7075 \mathrm{Al}$ alloy grown in alkaline silicate electrolyte containing $\mathrm{KMnO}_{4}$ additive. Surf. Coat. Technol. 2017, 329, 250-261. [CrossRef]

21. Wu, Y.-K.; Yang, Z.; Wang, R.Q.; Wu, G.R.; Chen, D.; Wang, D.D.; Liu, X.T.; Li, D.L.; Guo, C.H.; Yu, S.X.; et al. An investigation of microstructure evolution for plasma electrolytic oxidation (PEO) coated $\mathrm{Al}$ in an alkaline silicate electrolyte. Surf. Coat. Technol. 2018, 351, 136-152. [CrossRef]

22. Rahimi, S.; Khiabani, A.B.; Yarmand, B.; Kolahi, A. Comparison of corrosion and antibacterial properties of Al alloy treated by plasma electrolytic oxidation and anodizing methods. Mater. Today Proc. 2018, 5, 15667-15676. [CrossRef]

23. Yang, Z.; Wu, Y.K.; Zhang, X.Z.; Wang, D.D.; Liu, X.T.; Wu, G.R.; Li, D.L.; Yu, S.X.; Shen, D.J. An interesting anodic oxidation behavior of plasma electrolytic oxidation coatings fabricated on aluminum in alkaline phosphate electrolyte. Surf. Interfaces 2019, 16, 199-205. [CrossRef]

24. Nakajima, M.; Miura, Y.; Fushimi, K.; Habazaki, H. Spark anodizing behaviour of titanium and its alloys in alkaline aluminate electrolyte. Corros. Sci. 2019, 51, 1534-1539. [CrossRef]

25. Koo, B.H.; Lee, C.G.; Kim, U.J.; Lee, S.H.; Byon, E. Effects of electrolytes variation on formation of oxide layers of $6061 \mathrm{Al}$ alloys by plasma electrolytic oxidation. Trans. Nonferrous Met. Soc. China 2009, 19, 866-870.

26. Sang, S.B.; Kai, W.; Jung, Y.G.; Koo, B.H. Characteristic of $\mathrm{AlON}-\mathrm{Al}_{2} \mathrm{O}_{3}$ coatings on $\mathrm{Al} 6061$ alloy by electrolytic plasma processing in aluminate and nitride electrolytes. Surf. Coat. Technol. 2010, 204, 3196-3199.

27. Yerokhin, A.L.; Snizhko, L.O.; Gurevina, N.L.; Leyland, A.; Pilkington, A.; Matthews, A. Discharge characterization in plasma electrolytic oxidation of aluminium. J. Phys. D Appl. Phys. 2003, 36, 2110-2120. [CrossRef]

28. Li, X.J.; Zhang, M.; Wen, S.; Mao, X.; Huo, W.G.; Guo, Y.Y.; Wang, Y.X. Microstructure and wear resistance of micro-arc oxidation ceramic coatings prepared on 2A50 aluminum alloys. Surf. Coat. Technol. 2020, 394, 125853. [CrossRef]

29. Xue, W.B.; Deng, Z.W.; Lai, Y.C.; Chen, R.Y. Analysis of Phase Distribution for Ceramic Coatings Formed by Microarc Oxidation on Aluminum Alloy. J. Am. Ceram. Soc. 1998, 81, 1365-1368. [CrossRef]

30. Dehnavi, V.; Liu, X.Y.; Luan, B.L.; Shoesmith, D.W.; Rohani, S. Phase transformation in plasma electrolytic oxidation coatings on 6061 aluminum alloy. Surf. Coat. Technol. 2014, 251, 106-114. [CrossRef]

31. Cheng, Y.L.; Cao, J.H.; Mao, M.-K.; Peng, Z.M.; Skeldon, P.; Thompson, G.E. High growth rate, wear resistant coatings on an Al-Cu-Li alloy by plasma electrolytic oxidation in concentrated aluminate electrolytes. Surf. Coat. Technol. 2015, $269,74-82$. [CrossRef]

32. Hughes, A.E.; Hedges, M.M.; Sexton, B.A. Reactions at the $\mathrm{Al} / \mathrm{SiO}_{2} / \mathrm{SiC}$ layered interface. J. Mater. Sci. 1990, $25,4856-4865$. [CrossRef]

33. Wagner, C.D. X-ray photoelectron spectroscopy with X-ray photons of higher energy. J. Vac. Sci. Technol. 1978, 15, 518-523. [CrossRef]

34. Wang, Y.M.; Jiang, B.L.; Lei, T.Q.; Guo, L.X. Dependence of growth features of microarc oxidation coatings. Mater. Lett. 2004, 58, 1907-1911. [CrossRef]

35. Muhaffel, F.; Cimenoglu, H. Development of corrosion and wear resistant micro-arc oxidation coating on a magnesium alloy. Surf. Coat. Technol. 2019, 357, 822-832. [CrossRef] 